\title{
Sources of dietary protein and risk of hypertension in a general Dutch population
}

\author{
Wieke Altorf-van der Kuil ${ }^{1,2,3 *}$, Mariëlle F. Engberink ${ }^{1,2}$, Johanna M. Geleijnse ${ }^{1,2}$, Jolanda M. A. Boer ${ }^{3}$ \\ and W. M. Monique Verschuren ${ }^{3}$ \\ ${ }^{1}$ Top Institute Food and Nutrition, PO Box 557, 6700 AN, Wageningen, The Netherlands \\ ${ }^{2}$ Division of Human Nutrition, Wageningen University, PO Box 8129, 6700 EV, Wageningen, The Netherlands \\ ${ }^{3}$ National Institute for Public Health and the Environment (RIVM), PO Box 1, 3720 BA, Bilthoven, The Netherlands
}

(Submitted 27 July 2011 - Final revision received 30 November 2011 - Accepted 22 December 2011 - First published online 25 January 2012)

\section{Abstract}

Evidence suggests a small beneficial effect of dietary protein on blood pressure (BP), especially for plant protein. We examined the relationship between several types of dietary protein (total, plant, animal, dairy, meat and grain) and the risk of hypertension in a general population of 3588 Dutch adults, aged 26-65 years, who were free of hypertension at baseline. Measurements were done at baseline and after 5 and 10 years of follow-up. Hazard ratios (HR), with $95 \%$ CI, for incident hypertension were obtained in tertiles of energy-adjusted protein, using time-dependent Cox regression models. Models were adjusted for age, sex, BMI, education, smoking, baseline systolic BP, dietary confounders and protein from other sources (if applicable). Mean BP was 118/76 mmHg at baseline. Protein intake was 85 $(\mathrm{sD} 22) \mathrm{g} / \mathrm{d}$ (approximately $15 \%$ of energy) with $62 \%$ originating from animal sources. The main sources of protein were dairy products (28\%), meat (24\%) and grain (19\%). During the follow-up, 1568 new cases of hypertension were identified (44\% of the participants). Energy-adjusted intake of total protein, plant protein and animal protein was not significantly associated with hypertension risk (all HR approximately 1.00, $P>0.60$ ). Protein from grain showed a significant inverse association with incident hypertension, with a HR of $0.85\left(95 \%\right.$ CI $\left.0.73,1.00, P_{\text {trend }}=0.04\right)$ for the upper tertile $(\geq 18 \mathrm{~g} / \mathrm{d}) v$. the lower tertile $(<14 \mathrm{~g} / \mathrm{d})$, whereas dairy protein and meat protein were not associated with incident hypertension. In conclusion, higher intake of grain protein may contribute to the prevention of hypertension, which warrants confirmation in other population-based studies and randomised controlled trials.

\section{Key words: Hypertension: Dietary protein: Human subjects: Adults: Time-dependent survival analysis}

Health authorities emphasise the importance of dietary and lifestyle factors for the prevention of hypertension, which is a strong risk factor for $\mathrm{CVD}^{(1)}$. Even small effects of these dietary and lifestyle factors on blood pressure (BP) can have great public health impact. It has been estimated that a reduction in systolic BP of only $2 \mathrm{mmHg}$ may already result in a $6 \%$ reduction in fatal stroke and a $4 \%$ reduction in fatal $\mathrm{CHD}^{(2)}$. Dietary and lifestyle recommendations include physical activity, maintenance of a healthy body weight, reduced salt intake and moderation of alcohol consumption ${ }^{(2,3)}$. More recently, interest has grown into the influence of dietary patterns and macronutrient intakes on $\mathrm{BP}^{(4,5)}$.

A substantial body of evidence suggests a, possibly weak, beneficial effect of protein on BP, although findings are not conclusive $^{(6,7)}$. An important study in this respect is the large INTERSALT study (INTERnational study on SALT and blood pressure) in 10020 adults from thirty-two countries, in which a significant $0.5 \mathrm{mmHg}$ lower systolic BP was observed with each gram of $24 \mathrm{~h}$ urinary $\mathrm{N}$ (mean $\mathrm{N}$ excretion of 9.95 (SD $3 \cdot 11) \mathrm{g}$ ), as a biomarker for total protein intake ${ }^{(8)}$. This inverse association was confirmed by results of the OmniHeart randomised cross-over trial, in which the systolic BP of 164 healthy US adults decreased $1.4 \mathrm{mmHg}$ more after a 6-week high-protein diet compared with a diet high in carbohydrates ${ }^{(5)}$. However, no difference in BP change was found compared with a diet high in monounsaturated fat.

Protein intake is a rather heterogeneous exposure and specific types of protein (i.e. animal, plant) or protein from specific sources (e.g. dairy products, meat, grain) may differentially influence BP. In several observational studies ${ }^{(9-15)}$, the association with BP was investigated separately for plant protein and animal protein. Results were inconclusive, although there was a trend to a slightly more beneficial effect of plant protein on BP. In a prospective cohort study among 810 untreated pre- or mild hypertensives aged 25-79 years (PREMIER), the risk for developing hypertension was $21 \%$

Abbreviations: BP, blood pressure; en\%, percentage of energy; HR, hazard ratio.

*Corresponding author: W. Altorf-van der Kuil, fax +31 317 482782, email wieke.altorf-vanderKuil@wur.nl 
lower per percentage of energy (en\%) of plant protein intake, whereas for animal protein, no association was observed ${ }^{(13)}$. Also in a prospective cohort study among 5880 Hispanics (SUN (Seguimento Universidad de Navarra) cohort), a $50 \%$ reduction in hypertension risk with a high intake of plant protein was observed in the highest quintile compared with the lowest quintile, whereas intake of animal protein did not influence hypertension risk ${ }^{(10)}$. So far, data on specific protein sources in relation to $\mathrm{BP}$ are scarce. In a previous analysis in the Rotterdam Study, including 2241 Dutch adults aged $\geq 55$ years, we found no clear associations between protein from different dietary sources and 6-year incidence of hypertension ${ }^{(15)}$.

In the present analysis, we examined whether total protein intake and intake of plant and animal protein were associated with the risk of hypertension during 10 years of follow-up in a more general Dutch population-based cohort of 3588 adults, aged 26-65 years. In The Netherlands, approximately twothirds of dietary protein is from animal origin with the main sources being dairy products and meat, whereas plant protein is mainly obtained from grains ${ }^{(16)}$. We also analysed the associations for these protein sources.

\section{Methods}

\section{Design and study population}

We used data from the ongoing prospective Doetinchem cohort study, which has been described in detail elsewhere ${ }^{(17)}$. In brief, 12405 volunteers, aged 26-65 years, were examined between 1987 and 1991. A sample of these respondents ( $n$ 6386) was invited for follow-up examination in 1993-7, 1998-2002 and 2003-7. An extensive FFQ was implemented from 1993 onwards. The Medical Ethics Committee of The Netherlands Organization for Applied Scientific Research approved the study protocol of the Doetinchem Cohort Study and all participants signed the informed consent form.

In 1993 (subsequently referred to as 'baseline'), 6113 participants underwent physical examination, and BP measurements were obtained from 6100 participants. We excluded 1652 participants $(27 \%)$ with prevalent hypertension, defined as $\mathrm{BP} \geq 140 / 90 \mathrm{mmHg}$ and/or use of antihypertensive medication. Furthermore, we excluded 732 participants without information on hypertension status during both follow-up measurements. Finally, we excluded 128 participants with a history of CVD, self-reported diabetes at baseline, because of pregnancy at baseline or during the follow-up, or because of missing dietary data, leaving 3588 participants for the present analysis.

\section{Dietary assessment}

Dietary intake was assessed at baseline and during both follow-up measurements using a self-administered semiquantitative FFQ, developed for the international European Prospective Investigation into Cancer and Nutrition (EPIC) study, on 178 foods and beverages consumed during the preceding year ${ }^{(18)}$. Coloured photographs were used to facilitate the estimation of portion sizes, and seasonal variation in food intake was taken into account. Total energy and nutrient intakes were calculated using an extended version of the Dutch Food Composition Table of $1996^{(19)}$.

Animal protein was defined as protein from dairy products, meat, fish, eggs, and animal protein from mixed dishes. Plant protein included protein from soya, nuts, grains, fruits, vegetables, legumes, and plant protein from mixed dishes. Dairy protein was calculated as protein from milk, yogurt, coffee creamer, curd, pudding, porridge, custard, whipped cream and cheese, and meat protein included protein from all meat, meat products and poultry. Grain protein was defined as protein from rice, bread, pasta and plant protein in grain-containing bakery products.

The FFQ was validated in sixty-three men and fifty-eight women, and Pearson's correlation coefficients of 0.73 in men and 0.70 in women were found for reproducibility of energyadjusted total protein intake ${ }^{(20)}$. Additionally, the relative validity of the FFQ was assessed against twelve monthly $24 \mathrm{~h}$ recalls over a 1 -year period. Pearson's correlation coefficients for energy-adjusted protein intake after correction for intra-individual variation were 0.71 for men and 0.67 for women $^{(20)}$. The correlation coefficients with urinary $\mathrm{N}$ excretion in four $24 \mathrm{~h}$ urine samples at 3-month intervals were 0.56 for men and 0.69 for women, although data suggested a slight underestimation of protein intake by the FFQ (mean percentage of underestimation: $7 \%$ for men and $12 \%$ for women $)^{(20)}$. For types and sources of protein (e.g. from plant, animal, dairy products, grain), the FFQ was not validated. However, correlations with $24 \mathrm{~h}$ recalls were good for milk and milk products $\left(r_{\text {men }} 0.69 ; r_{\text {women }}\right.$ 0.77) and bread ( $\left.r_{\text {men }} 0 \cdot 76 ; r_{\text {women }} 0 \cdot 78\right)$, whereas correlations for meat were lower, especially for men $\left(r_{\text {men }} 0.39 ; r_{\text {women }} 0.59\right)^{(18)}$.

\section{Blood pressure}

$\mathrm{BP}$ was measured by a trained technician using a random-zero sphygmomanometer, with the participants in the sitting position. Systolic BP was recorded at the appearance of sounds (first-phase Korotkoff), and diastolic BP was recorded at the disappearance of sounds (fifth-phase Korotkoff). BP was measured twice, separated by a pulse count. The mean of two measurements was used for data analysis. During physical examination, regular audits were performed to check adherence to the BP-measuring protocol (e.g. resting time, adequate cuff size). Hypertension was defined as systolic BP at least $140 \mathrm{mmHg}$ or diastolic BP at least $90 \mathrm{mmHg}$ or use of antihypertensive medication.

\section{Assessment of potential confounders}

Information on potential confounders was collected at baseline and during both follow-up examinations. Body weight (to the nearest $0 \cdot 1 \mathrm{~kg}$ ) and height (to the nearest $0.5 \mathrm{~cm}$ ) were measured with participants wearing light indoor clothing without shoes, and BMI $\left(\mathrm{kg} / \mathrm{m}^{2}\right)$ was calculated. Data on age, sex, education, lifestyle factors, history of major diseases, medication use and any prescribed diets were collected using questionnaires. An extensive questionnaire on physical activity was introduced in 1994 and was completed by 2936 participants $(81 \%)$. Questionnaire data were used to create 
variables on alcohol intake (none, moderate and high), smoking status (current smoker/non-smoker), educational level (three categories) and physical activity (four categories, ranging from inactive to very active ${ }^{(21)}$ ).

\section{Statistical analysis}

Intake of total protein and different types of protein was first adjusted for total energy intake according to the residual method $^{(22)}$. Baseline characteristics of the study population across tertiles of energy-adjusted total protein intake are presented as means and standard deviations, percentages or medians with interquartile ranges.

We used time-dependent Cox regression models to calculate hazard ratios (HR) with 95\% CI for the association between dietary protein intake and 10-year incidence of hypertension. We defined the exposure as the cumulative average energyadjusted protein intake to reduce measurement error and to estimate long-term intake. $P$ for trend was estimated by modelling the median intake of baseline tertiles.

For the participants who did not develop hypertension during the follow-up, we computed survival time as years from baseline to the end of the study period (i.e. 10-year examination visit) or until the end of the follow-up. For the participants who developed hypertension, we attributed 2.5 years of follow-up if hypertension was present at the 5-year examination visit, and 7.5 years of follow-up if hypertension was present at the 10-year examination visit.

The basic model (model 1) included age and sex. In model 2, we further adjusted for BMI, educational level, smoking, alcohol use and baseline systolic BP. The full model (model 3) additionally included daily intake of total energy, SFA, PUFA, carbohydrates, fibre, $\mathrm{Ca}, \mathrm{Mg}$ and $\mathrm{K}$, and protein intake from other sources than the one under study, if applicable. Age, sex and lifestyle covariates were updated for each measurement round. For dietary covariates, the cumulative average intake was calculated up to each measurement round. Dietary Ca was strongly correlated with dairy protein intake $(r 0.82)$. Therefore, we conducted an additional analysis without $\mathrm{Ca}$ in the model to check for multicollinearity.

To mimic a situation in which dietary protein was exchanged for dietary carbohydrates, we performed an additional analysis using the full model (model 3) with MUFA as an additional covariate instead of carbohydrates. To investigate whether physical activity confounded the protein-BP associations, we performed a sensitivity analysis per $5 \mathrm{~g}$ of total, plant and animal protein in the subgroup of 2892 participants (81\%) with complete data on physical activity, using the full model with and without additional adjustment for physical activity.

Finally, we performed a number of pre-defined subgroup analyses for total, plant and animal protein, in the strata of age $(<45$ and $\geq 45$ years $)$, sex, overweight status $\left(<25\right.$ and $\left.\geq 25 \mathrm{~kg} / \mathrm{m}^{2}\right)$ and baseline systolic BP $(<130$ and $\geq 130 \mathrm{mmHg}$ ), using the full model. Data analysis was performed using SAS version 9.1 (SAS Institute, Inc.) and a two-sided $P$ value of $<0.05$ was considered statistically significant.

\section{Results}

\section{Descriptive statistics}

The mean age of the total study population was 44 (SD 10) years and 44\% were male. Mean BMI was 25 (SD 3) kg/m² and $43 \%$ of the participants were overweight or obese (BMI $\geq 25 \mathrm{~kg} / \mathrm{m}^{2}$ ). Baseline BP was $118 / 76 \mathrm{mmHg}$. Mean protein intake was 85 (SD 22) g/d (approximately 15 en\%), of which $63 \%$ originated from animal sources. Major sources of animal protein intake were dairy products ( $45 \%$ of animal protein intake) and meat (38\%). Plant protein intake mainly comprised grain protein (51\%), whereas the next main sources were potatoes $(11 \%)$, vegetables $(7 \%)$, fruits $(4 \%)$ and legumes (2\%).

Baseline characteristics and dietary intake of the study population according to tertiles of energy-adjusted total protein intake are shown in Table 1 . The percentage of males increased significantly across tertiles of energy-adjusted protein intake as well as the number of overweight participants. With regard to dietary intake, the higher intake of total dietary protein in the highest tertiles was mainly reflected in differences in animal protein intake, whereas the intake of plant protein was relatively constant over tertiles of energy-adjusted total protein intake. Also, intake of fat and carbohydrates did not differ significantly across consecutive tertiles, although carbohydrate intake was somewhat higher in the lowest category of total protein. The intake of $\mathrm{K}, \mathrm{Mg}$ and Ca increased significantly across tertiles of energy-adjusted total protein intake.

\section{Protein intake and incident hypertension}

After a mean follow-up time of $7 \cdot 5$ (sD 2.9) years (26500 personyears), 1568 new cases of hypertension were identified. The number of incident hypertension cases in increasing baseline tertiles of energy-adjusted total protein was, respectively, 57, 58 and 63 per 1000 person-years. Associations between protein intake and incident hypertension are shown in Table 2. Intake of total, plant and animal protein was not clearly associated with incident hypertension, with all fully adjusted HR being close to 1.00 (all $P_{\text {trend }}>0 \cdot 60$ ). When the full model was adjusted for MUFA instead of carbohydrates, the HR of upper tertile $v$. lower tertile were 1.04 (95\% CI $0.89,1.23)$ for total protein $\left(P_{\text {trend }}=0.62\right), 0.96(95 \%$ CI $0.79,1.15)$ for plant protein $\left(P_{\text {trend }}=0.59\right)$ and $1.00(95 \%$ CI $0.84,1.19)$ for animal protein $\left(P_{\text {trend }}=0.98\right)$.

Within the subgroup of 2892 participants for whom data on physical activity were available (21566 person-years), 1217 new cases of hypertension were identified. In this subgroup, we found identical HR per $5 \mathrm{~g}$ of total, plant and animal protein both with and without additional adjustment for physical activity (respectively 1.02, 0.97-1.06; 1.01, 0.90-1.13; 1.02, 0.97-1.06). Pre-defined subgroup analyses showed that the association between protein and hypertension risk did not vary among strata of age, sex, BMI or baseline BP (all $P$ for interaction $>0 \cdot 15$ ).

When focusing on the main protein sources, intake of dairy protein and meat protein was not associated with incident hypertension (Table 2). Sensitivity analysis excluding dietary 
Table 1. Baseline characteristics by baseline tertiles of energy-adjusted total protein intake of 3588 Dutch adults (26-65 years), without hypertension or use of antihypertensive medication at baseline

(Mean values, standard deviations, medians, interquartile ranges and percentages)

\begin{tabular}{|c|c|c|c|c|c|c|c|c|c|c|}
\hline & \multicolumn{10}{|c|}{ Tertile of energy-adjusted total protein intake } \\
\hline & \multicolumn{3}{|c|}{$<81 \mathrm{~g} / \mathrm{d}(n 1184)$} & \multicolumn{3}{|c|}{$81-89 \mathrm{~g} / \mathrm{d}(n 1184)$} & \multicolumn{3}{|c|}{$>89 \mathrm{~g} / \mathrm{d}(n 1220)$} & \multirow[b]{2}{*}{$P_{\text {trend }}$} \\
\hline & Mean & SD & en $\%$ & Mean & SD & en $\%$ & Mean & SD & en $\%$ & \\
\hline Median intake (g/d) & 75 & & & 85 & & & 95 & & & \\
\hline Age (years) & 44 & 10 & & 44 & 9 & & 45 & 10 & & 0.03 \\
\hline \multicolumn{11}{|l|}{ Sex } \\
\hline Men (\%) & 52 & & & 56 & & & 57 & & & 0.02 \\
\hline BMI $\left(\mathrm{kg} / \mathrm{m}^{2}\right)$ & $24 \cdot 4$ & $3 \cdot 3$ & & 24.7 & $3 \cdot 1$ & & $25 \cdot 3$ & $3 \cdot 3$ & & $<0.01$ \\
\hline Overweight* $(\%)$ & 38 & & & 43 & & & 48 & & & $<0.01$ \\
\hline \multicolumn{11}{|l|}{ Education } \\
\hline High $(\%)$ & 19 & & & 23 & & & 20 & & & 0.21 \\
\hline Systolic blood pressure $(\mathrm{mmHg})$ & 118.2 & $10 \cdot 6$ & & $117 \cdot 6$ & $10 \cdot 8$ & & $117 \cdot 8$ & $10 \cdot 3$ & & 0.39 \\
\hline Diastolic blood pressure $(\mathrm{mmHg})$ & $75 \cdot 6$ & 7.7 & & $75 \cdot 7$ & 7.7 & & $75 \cdot 8$ & 7.6 & & 0.58 \\
\hline Alcohol among consumers (glasses/d†) & & & & & & & & & & $<0.01$ \\
\hline Median & 1.4 & & & 1.1 & & & 1.0 & & & \\
\hline Interquartile range & $0.7-2.9$ & & & $0.7-2.1$ & & & $0.6-2.0$ & & & \\
\hline Current smokers (\%) & 38 & & & 28 & & & 28 & & & $<0.01$ \\
\hline \multicolumn{11}{|l|}{ Dietary intake } \\
\hline Total energy (kJ/d) & 9752 & 2802 & & 9198 & 2399 & & 9627 & 2690 & & 0.27 \\
\hline Total protein $(\mathrm{g} / \mathrm{d})$ & 75 & 20 & 13 & 82 & 18 & 15 & 98 & 23 & 18 & $<0.01$ \\
\hline Plant protein $(\mathrm{g} / \mathrm{d})$ & 32 & 10 & 6 & 31 & 9 & 6 & 32 & 10 & 6 & 0.94 \\
\hline Grain protein $\neq(\mathrm{g} / \mathrm{d})$ & 16 & 7 & 3 & 16 & 6 & 3 & 17 & 7 & 3 & $<0.01$ \\
\hline Animal protein $(\mathrm{g} / \mathrm{d})$ & 43 & 13 & 8 & 51 & 12 & 10 & 65 & 16 & 12 & $<0.01$ \\
\hline Dairy protein§ (g/d) & 18 & 8 & 3 & 22 & 9 & 4 & 32 & 13 & 6 & $<0.01$ \\
\hline Meat protein \| (g/d) & 17 & 9 & 3 & 20 & 8 & 4 & 24 & 9 & 4 & $<0.01$ \\
\hline Total fat $(\mathrm{g} / \mathrm{d})$ & 92 & 31 & 35 & 89 & 28 & 36 & 93 & 31 & 36 & 0.57 \\
\hline Saturated fat $(\mathrm{g} / \mathrm{d})$ & 38 & 13 & 14 & 37 & 12 & 15 & 40 & 13 & 15 & $<0.01$ \\
\hline Monounsaturated fat $(\mathrm{g} / \mathrm{d})$ & 35 & 12 & 13 & 34 & 11 & 14 & 35 & 12 & 13 & 0.70 \\
\hline Polyunsaturated fat $(\mathrm{g} / \mathrm{d})$ & 19 & 7 & 7 & 17 & 6 & 7 & 17 & 7 & 7 & $<0.01$ \\
\hline Carbohydrates $(\mathrm{g} / \mathrm{d})$ & 274 & 80 & 48 & 248 & 69 & 46 & 251 & 77 & 44 & $<0.01$ \\
\hline $\mathrm{K}(\mathrm{mg} / \mathrm{d})$ & 3638 & 908 & & 3739 & 796 & & 4171 & 939 & & $<0.01$ \\
\hline$M g(m g / d)$ & 358 & 99 & & 367 & 84 & & 409 & 103 & & $<0.01$ \\
\hline $\mathrm{Ca}(\mathrm{mg} / \mathrm{d})$ & 936 & 313 & & 1083 & 320 & & 1409 & 471 & & $<0.01$ \\
\hline Fibre $(\mathrm{g} / \mathrm{d})$ & 25 & 7 & & 25 & 6 & & 26 & 7 & & $<0.01$ \\
\hline
\end{tabular}

en\%, percentage of energy.

${ }^{*} \mathrm{BMI} \geq 25 \mathrm{~kg} / \mathrm{m}^{2}$.

†Percentage of alcohol consumers in all tertiles approximately $62 \%$; alcohol consumption is presented as medians with interquartile ranges because of skewed distribution.

$\ddagger$ Protein intake from rice, bread, pasta and plant protein in grain-containing bakery products.

$\S$ Protein intake from milk, yogurt, coffee creamer, curd, pudding, porridge, custard, whipped cream and cheese.

\| Protein intake from meat, meat products and poultry.

Ca from the multivariable analysis on dairy protein indicated some degree of multicollinearity (i.e. the width of the CI slightly decreased). Leaving $\mathrm{Ca}$ out of the model, however, yielded essentially similar results: HR of the third tertile compared with the lowest tertile: $0.99,0 \cdot 84-1 \cdot 17$. Intake of grain protein showed a significant $15 \%$ lower risk of hypertension in the upper tertile compared with the lowest tertile (multivariate HR $0.85,95 \%$ CI $\left.0.73,1.00 ; P_{\text {trend }}=0.04\right)$. Other sources of plant protein (i.e. potatoes, legumes, vegetables and fruits) were not related to hypertension risk (all $P>0 \cdot 30$, data not shown).

\section{Discussion}

In this prospective cohort study among 3588 participants without hypertension at baseline, intake of total, plant and animal protein was not associated with 10-year incidence of hypertension. Also, intake of protein from dairy products and meat, the main sources of animal protein, was not associated with hypertension risk. A high intake of grain protein was significantly associated with a $15 \%$ lower risk for hypertension.
The present analyses were conducted in a population-based cohort with repeated measurements of dietary intake and lifestyle over 10 years of follow-up ${ }^{(17)}$. Because dietary intake was assessed three times during the follow-up, we were able to reduce measurement error and estimate long-term protein intake by using the cumulative average in time-dependent Cox models. Extensive data were available on potential confounders, although baseline assessment of physical activity was not performed in participants who were enrolled before 1994. However, similar protein-BP associations were obtained with and without adjustment for physical activity in participants with complete data.

The self-administered FFQ of the present study has been validated against $24 \mathrm{~h}$ dietary recalls and $24 \mathrm{~h}$ urine samples ${ }^{(20)}$. Correlations were good with correlation coefficients for total protein, plant protein and animal protein being $>0.60$, indicating that participants could be adequately ranked according to their protein intake. The FFQ was not validated for protein from specific sources, but correlations for milk and bread, as surrogate markers for dairy and grain 
Table 2. Cumulative average protein intake in relation to 10 -year incidence of hypertension in 3588 Dutch adults (25-65 years) ${ }^{\star}$ (Hazard ratios and $95 \%$ confidence intervals)

\begin{tabular}{|c|c|c|c|c|c|c|}
\hline & \multicolumn{2}{|c|}{ Model 1† } & \multicolumn{2}{|c|}{ Model $2 \ddagger$} & \multicolumn{2}{|c|}{ Model 3§ } \\
\hline & $\begin{array}{c}\text { Hazard ratio } \\
\text { of hypertension }\end{array}$ & $95 \% \mathrm{Cl}$ & $\begin{array}{c}\text { Hazard ratio } \\
\text { of hypertension }\end{array}$ & $95 \% \mathrm{Cl}$ & $\begin{array}{c}\text { Hazard ratio } \\
\text { of hypertension }\end{array}$ & $95 \% \mathrm{Cl}$ \\
\hline \multicolumn{7}{|l|}{ Total protein (g/d) } \\
\hline$<81$ & 1.00 & Ref & 1.00 & Ref & 1.00 & Ref \\
\hline $81-89$ & 1.05 & $0.93,1.18$ & 1.06 & $0.93,1.19$ & 1.00 & $0.88,1 \cdot 15$ \\
\hline$\geq 89$ & $1 \cdot 16$ & $1 \cdot 02,1 \cdot 31$ & $1 \cdot 11$ & $0.98,1.25$ & 1.01 & $0.85,1.19$ \\
\hline$P_{\text {trend }} \|$ & \multicolumn{2}{|c|}{0.02} & \multicolumn{2}{|c|}{0.11} & \multicolumn{2}{|c|}{0.93} \\
\hline Plant protein $(\mathrm{g} / \mathrm{d})$ & & & & & & \\
\hline$<30$ & 1.00 & Ref & 1.00 & Ref & 1.00 & Ref \\
\hline $30-34$ & 0.87 & $0.77,0.98$ & 0.91 & $0.81,1.03$ & 0.92 & $0.80,1.06$ \\
\hline$\geq 34$ & 0.80 & $0.71,0.90$ & 0.91 & $0.80,1.03$ & 0.96 & $0.80,1 \cdot 16$ \\
\hline $\begin{array}{l}P_{\text {trendll }} \\
\text { Animal protein }(\mathrm{g} / \mathrm{d})\end{array}$ & \multicolumn{2}{|c|}{$<0.01$} & \multicolumn{2}{|c|}{0.12} & \multicolumn{2}{|c|}{0.65} \\
\hline $\begin{array}{l}\text { Animali protein }(\mathrm{g} / \mathrm{d}) \\
<48\end{array}$ & 1.00 & Ref & 1.00 & Ref & 1.00 & Ref \\
\hline $48-57$ & 1.01 & $0.89,1 \cdot 14$ & 0.97 & $0.85,1 \cdot 10$ & 0.90 & $0.79,1.03$ \\
\hline$\geq 57$ & 1.23 & $1.09,1.39$ & 1.11 & $0.98,1.26$ & 0.97 & $0.81,1 \cdot 15$ \\
\hline$P_{\text {trend }} \|$ & \multicolumn{2}{|c|}{$<0.01$} & \multicolumn{2}{|c|}{0.08} & \multicolumn{2}{|c|}{0.70} \\
\hline Dairy protein (g/d) & & & & & & \\
\hline$<19$ & 1.00 & Ref & 1.00 & Ref & 1.00 & Ref \\
\hline $19-27$ & 0.89 & $0.79,1.01$ & 0.94 & $0.83,1.06$ & 0.91 & $0.78,1.05$ \\
\hline$\geq 27$ & 1.01 & $0.89,1.14$ & 1.07 & $0.94,1.21$ & 1.00 & $0.81,1.25$ \\
\hline$P_{\text {trendll }}$ & \multicolumn{2}{|c|}{0.77} & \multicolumn{2}{|c|}{0.28} & \multicolumn{2}{|c|}{0.97} \\
\hline Meat protein (g/d) & & & & & & \\
\hline$<17$ & 1.00 & Ref & 1.00 & Ref & 1.00 & Ref \\
\hline $17-24$ & $1 \cdot 12$ & $0.99,1.26$ & 1.01 & $0.89,1.14$ & 0.97 & $0 \cdot 85,1 \cdot 10$ \\
\hline$\geq 24$ & 1.29 & $1.14,1.46$ & 1.09 & $0.95,1.23$ & 0.99 & $0.85,1 \cdot 16$ \\
\hline$P_{\text {trendll }}$ & \multicolumn{2}{|c|}{$<0.01$} & \multicolumn{2}{|c|}{0.22} & \multicolumn{2}{|c|}{0.92} \\
\hline Grain protein (g/d) & & & & & & \\
\hline$<14$ & 1.00 & Ref & 1.00 & Ref & 1.00 & Ref \\
\hline $14-18$ & 0.88 & $0.79,0.99$ & 0.91 & $0.81,1.03$ & 0.91 & $0.80,1.03$ \\
\hline$\geq 18$ & 0.76 & $0.68,0.87$ & 0.82 & $0.72,0.93$ & 0.85 & $0.73,1.00$ \\
\hline$P_{\text {trendll }}$ & \multicolumn{2}{|c|}{$<0.01$} & \multicolumn{2}{|c|}{$<0.01$} & \multicolumn{2}{|c|}{0.04} \\
\hline
\end{tabular}

Ref, reference group.

${ }^{\star}$ All types of protein were energy adjusted according to the residual method ${ }^{(22)}$

tAdjusted for age and sex.

$\ddagger$ Additionally adjusted for BMI, educational level, smoking, alcohol use and baseline systolic blood pressure.

$\S$ Additionally adjusted for intake of total energy, SFA, PUFA, carbohydrates, fibre, $\mathrm{Ca}, \mathrm{Mg}, \mathrm{K}$ and (in analyses of protein types) for other protein types.

$\| P_{\text {trend }}$ was estimated by modelling the median intake of baseline tertiles.

protein, were good $(>0 \cdot 65)$. However, correlations for meat

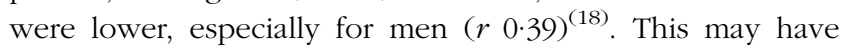
caused misclassification of participants according to meat protein intake and, as a consequence, the results for this type of protein may have been biased towards no association. To explore the potential influence of protein sources on BP in future epidemiological studies, identification of biological markers for intake of protein from specific sources such as meat could be useful.

A substantial body of evidence suggests a, possibly weak, beneficial effect of protein on BP, as summarised previously ${ }^{(6)}$. We adjusted our estimates among others for energy, carbohydrates, SFA and PUFA, and, in this way, we mimicked a situation in which only intake of protein and MUFA do vary. However, in the large OmniHeart cross-over feeding trial among 164 participants, no difference in BP effect was found after a high-protein diet compared with a high-MUFA diet, which may explain our lack of result for total protein and hypertension risk. In contrast, in the OmniHeart study, a beneficial BP effect was observed after the high-protein diet compared with a diet high in carbohydrates ${ }^{(5)}$. Therefore, to mimic the exchange of protein with carbohydrates, we performed an additional analysis using the full model, with adjustment for MUFA instead of carbohydrates. However, this did not essentially change the present results. Further research is needed to investigate the BP effect after the exchange of different macronutrients.

Several observational studies have been conducted that investigated the association with BP separately for plant and animal protein, showing inconclusive results, although in some studies, plant protein seemed to be more beneficial than animal protein. In the present study, we did not observe a difference between these two types of protein. The discrepancy of the present findings with those in the PREMIER study in which the risk for developing hypertension was $21 \%$ lower per en $\%$ of plant protein intake ${ }^{(13)}$ may be found in the fact that only individuals with elevated BP were included. Possibly these adults were more sensitive to BPlowering effects of plant protein. In the Spanish SUN cohort, a $50 \%$ risk reduction for hypertension was found for plant protein ${ }^{(10)}$. However, possibly the distribution of protein sources between the present study and the SUN cohort was 
different. In Spain, on average, more legumes are eaten, and residual confounding from isoflavones in soya may play a role.

Evidence on specific sources of protein in relation to $\mathrm{BP}$ is scarce $^{(6)}$. A few observational studies have been conducted in which urinary taurine was used as a biomarker of dietary seafood protein, showing inverse associations ${ }^{(23-25)}$. In The Netherlands, the intake of seafood protein is very low (approximately 3\% of total protein intake ${ }^{(16)}$ ), so we could not investigate this association in the present study. Furthermore, in two trials, the effect of meat protein on BP was investigated, but no significant effect was observed. However, in a previous analysis in the Rotterdam Study, including 2241 Dutch adults aged $\geq 55$ years, we observed a direct association of meat protein with the incidence of hypertension in those aged $\geq 70$ years ${ }^{(15)}$. In the present analysis, we did not observe an association between meat protein and hypertension. However, because of ageing, kidney function in the elderly of the Rotterdam Study may have been declined ${ }^{(26)}$, which affects handling of high protein intake, and, consequently, increases the risk of hypertension. The difference in the results of the Rotterdam Study may, therefore, be explained by the younger age of the current population.

With high grain protein intake, we observed a significant $15 \%$ reduced hypertension risk. Although the mechanisms through which protein (sources) may reduce BP are largely unknown, amino acid composition may play a role. In the INTERMAP study (INTERnational study of Macronutrients and Micronutrients and blood Pressure), a 2 SD higher intake of glutamic acid ( $4.7 \%$ of total protein) was associated with $1.5 \mathrm{mmHg}$ lower systolic BP and $1.0 \mathrm{mmHg}$ lower diastolic $\mathrm{BP}^{(27)}$. A major contributor to grain protein intake in The Netherlands is wheat from bread ${ }^{(28)}$, which contains high levels of glutamic acid $\left(31 \cdot 4 \%{ }^{(29)}\right)$. However, we can also not exclude that residual confounding by healthy dietary and lifestyle factors, associated with high grain protein intake, is responsible for the observed associations in the present study.

In conclusion, a higher intake of grain protein may contribute to the prevention of hypertension, which warrants confirmation in other population-based studies and randomised controlled trials.

\section{Acknowledgements}

The authors thank the epidemiologists and fieldworkers of the Municipal Health Service in Doetinchem for their contribution to the data collection for this study. The project director is W. M. M. V., logistic management was provided by P. Vissink and data management was provided by A. Blokstra. The Doetinchem Cohort Study was financially supported by the Ministry of Health, Welfare and Sport of the Netherlands and the National Institute for Public Health and the Environment. For the present analysis, Wageningen University was supported by the Top Institute Food and Nutrition, which is a public/private partnership that generates vision on scientific breakthroughs in food and nutrition, resulting in the development of innovative products and technologies. Partners are major Dutch Food companies and research organisations. The funders had no role in the study design, data collection and analysis, decision to publish, or preparation of the manuscript. J. M. G. obtained an unrestricted grant from the Alpro Foundation, Belgium for an epidemiological analysis on fruit and vegetable intake in relation to CVD, which bears no relation to the present study. None of the other authors has a conflict of interest. W. M. M. V., J. M. A. B., M. F. E., J. M. G. and W. A.-V. d. K. designed the research; W. M. M. V. and J. M. A. B. conducted the research; W. A.-V. d. K. analysed the data; W. A.-v. d. K., M. F. E. and J. M. G. wrote the manuscript; W. A.-v. d. K. has the primary responsibility for the final content of the manuscript. All authors read and approved the final manuscript.

\section{References}

1. Lewington S, Clarke R, Qizilbash N, et al. (2002) Age-specific relevance of usual blood pressure to vascular mortality: a meta-analysis of individual data for one million adults in 61 prospective studies. Lancet 360, 1903-1913.

2. Whelton PK, He J, Appel LJ, et al. (2002) Primary prevention of hypertension: clinical and public health advisory from the National High Blood Pressure Education Program. JAMA 288, 1882-1888.

3. Appel LJ, Brands MW, Daniels SR, et al. (2006) Dietary approaches to prevent and treat hypertension: a scientific statement from the American Heart Association. Hypertension 47, 296-308.

4. Appel LJ, Moore TJ, Obarzanek E, et al. (1997) A clinical trial of the effects of dietary patterns on blood pressure. $N$ Engl J Med 336, 1117-1124.

5. Appel LJ, Sacks FM, Carey VJ, et al. (2005) Effects of protein, monounsaturated fat, and carbohydrate intake on blood pressure and serum lipids: results of the OmniHeart randomized trial. JAMA 294, 2455-2464.

6. Altorf-van der Kuil W, Engberink MF, Brink EJ, et al. (2010) Dietary protein and blood pressure: a systematic review. PLOS ONE 5, e12102.

7. Savica V, Bellinghieri G \& Kopple JD (2010) The effect of nutrition on blood pressure. Annu Rev Nutr 30, 365-401.

8. Stamler J, Elliott P, Kesteloot H, et al. (1996) Inverse relation of dietary protein markers with blood pressure. Findings for 10,020 men and women in the INTERSALT Study. INTERSALT Cooperative Research Group. INTERnational study of SALT and blood pressure. Circulation 94, 1629-1634.

9. Stamler J, Liu K, Ruth KJ, et al. (2002) Eight-year blood pressure change in middle-aged men: relationship to multiple nutrients. Hypertension 39, 1000-1006.

10. Alonso A, Beunza JJ, Bes-Rastrollo M, et al. (2006) Vegetable protein and fiber from cereal are inversely associated with the risk of hypertension in a Spanish cohort. Arch Med Res 37, 778-786.

11. Elliott P, Stamler J, Dyer AR, et al. (2006) Association between protein intake and blood pressure: the INTERMAP Study. Arch Intern Med 166, 79-87.

12. Masala G, Bendinelli B, Versari D, et al. (2008) Anthropometric and dietary determinants of blood pressure in over 7000 Mediterranean women: the European Prospective Investigation into Cancer and Nutrition-Florence cohort. J Hypertens 26, 2112-2120.

13. Wang YF, Yancy WY Jr, Yu D, et al. (2008) The relationship between dietary protein intake and blood pressure: results from the PREMIER study. J Hum Hypertens 22, 745-754.

14. Umesawa M, Sato S, Imano H, et al. (2009) Relations between protein intake and blood pressure in Japanese 
men and women: the Circulatory Risk in Communities Study (CIRCS). Am J Clin Nutr 90, 377-384.

15. Altorf-van der Kuil W, Engberink MF, van Rooij FJ, et al. (2010) Dietary protein and risk of hypertension in a Dutch older population: the Rotterdam Study. J Hypertens 28, 2394-2400.

16. Halkjær J, Olsen A, Bjerregaard LJ, et al. (2009) Intake of total, animal and plant proteins, and their food sources in 10 countries in the European Prospective Investigation into Cancer and Nutrition. Eur J Clin Nutr 63, S16-S36.

17. Verschuren WMM, Blokstra A, Picavet HSJ, et al. (2008) Cohort profile: The Doetinchem Cohort Study. Int J Epidemiol 37, 1236-1241.

18. Ocké MC, Bueno-De-Mesquita HB, Goddijn HE, et al. (1997) The Dutch EPIC Food Frequency Questionnaire. I. Description of the questionnaire, and relative validity and reproducibility for food groups. Int J Epidemiol 26, S37-S48.

19. Stiching-Nederlands-Voedingsstoffen bestand (1998) Nederlands Voedingsstoffen bestand NEVO table 1996 (Dutch Nutrient Data Base 1996). The Hague: Voorlichtingsbureau voor de Voeding

20. Ocké MC, Bueno-De-Mesquita HB, Pols MA, et al. (1997) The Dutch EPIC Food Frequency Questionnaire. II. Relative validity and reproducibility for nutrients. Int J Epidemiol 26, S49-S58.

21. Blokstra A, Bueno-de-Mesquita HB, Seidell JC, et al. (2005) Monitoring of Risk Factors and Health in The Netherlands (MORGEN-Project) 1993-1997. Lifestyle and Risk Factors: Prevalences and Trends 2005. RIVM Report 263200008. Bilthoven: RIVM.
22. Willett WC, Howe GR \& Kushi LH (1997) Adjustment for total energy intake in epidemiologic studies. Am J Clin Nutr $\mathbf{6 5}$, 1220S-1228S.

23. Zhou B, Zhang X, Zhu A, et al. (1994) The relationship of dietary animal protein and electrolytes to blood pressure: a study on three Chinese populations. Int J Epidemiol 23, 716-722.

24. Liu L, Mizushima S, Ikeda K, et al. (2000) Comparative studies of diet-related factors and blood pressure among Chinese and Japanese: results from the China-Japan cooperative research of the WHO-CARDIAC Study. Cardiovascular Disease and Alimentary Comparison. Hypertens Res 23, 413-420.

25. Liu L, Liu L, Ding Y, et al. (2001) Ethnic and environmental differences in various markers of dietary intake and blood pressure among Chinese Han and three other minority peoples of China: results from the WHO Cardiovascular Diseases and Alimentary Comparison (CARDIAC) Study. Hypertens Res 24, 315-322.

26. Fliser D (2008) Assessment of renal function in elderly patients. Curr Opin Nephrol Hypertens 17, 604-608.

27. Stamler J, Brown IJ, Daviglus ML, et al. (2009) Glutamic acid, the main dietary amino acid, and blood pressure: the intermap study (international collaborative study of macronutrients, micronutrients and blood pressure). Circulation 120, 221-228.

28. Anonymous (1998) Zo eet Nederland, Resultaten van de voedselconsumptiepeiling 1997-1998 (Dutch Food Consumption Survey of 1997-1998). The Hague: Dutch Nutrition Center.

29. Belitz H-D, Grosch W \& Schieberle P (2009) Amino acids, peptides, proteins. In Food Chemistry, pp. 8-92. Berlin and Heidelberg: Spring-Verlag. 